\title{
Obituary
}

\section{Tang Tsou: A Memorial}

\author{
Stuart R. Schram
}

For half a century, arguments have raged as to whether China can best be understood in the light of its own unique history and culture, or whether it should be analysed in terms of the same categories used by the practitioners of various disciplines in dealing with other societies. There has also been disagreement as to whether, because of the length and richness of the record of China's past, history, rather than political science or sociology, should play the primary role in the study of that country. Tang Tsou, who died on 7 August 1999, at the age of 80, was one of the very few who did not need to choose among these approaches, because he was a master of them all. Hans Morgenthau, in his foreword to Tang's first major publication, America's Failure in China 1941-1950 (1963), said of that work: "It is both history in the grand style and political science at its best." That judgement applies equally well to the whole of Tang's scholarly achievement.

Summing up the conclusions he had reached in America's Failure in China, Tang asserted that the decisive factor in determining the successes and failures of American China policy was "the imbalance between ends and means." He continued:

From one point of view, this imbalance takes the form of an unwillingness and, at times, an inability to use military power purposefully to achieve political objectives. From another point of view, it appears as an unwillingness and inability to abandon unattainable goals in order to avoid entanglement in a hopeless cause.

It is hard to deny that these tendencies have frequently been visible in the domain of United States foreign policy in the 49 years since the collapse of MacArthur's adventure in Korea, from Vietnam to Haiti and from Somalia to the Balkans.

After establishing himself as a specialist in international relations, Tang turned his attention to the study of China's internal politics. He noted at the beginning of the volume containing eight of his most important contributions in the latter domain (The Cultural Revolution and Post-Mao Reforms, 1986), that the occasion for this shift was provided by the Chicago conferences on China in February 1967, where I first had the privilege of making his acquaintance and of beginning a friendship which would continue for thirty years. This transition is symbolized by the fact that while he was the sole editor of the conference volume on foreign policy, his own contributions appeared in the volume on China's Heritage and the Communist Political System. The details of this account, entitled "Revolution, reintegration, and crisis in Communist China: a framework for analysis," were rapidly overtaken by events, but Tang's conclusion still stands. In the Great Leap Forward, he wrote, Mao's thought and policies produced an economic disaster, and in the Great

(C) The China Quarterly, 1999 
Proletarian Cultural Revolution, Mao's thought and policies were likely to have serious consequences not only for cultural and academic life, but for the political system:

What we have witnessed is the tragedy of a once effective doctrine which has outlived its usefulness and the tragedy of a once impressive political system which has rested on the foundation of a total ideology rather than on a consensus or agreement on fundamentals.

This is not the place for a summary of the other seven articles in this volume, or of Tang's other writings, which include an extremely detailed case study of the Dazhai model based in part on fieldwork in the area ("Policy change at the national summit and institutional transformation at the local level: the case of Tachai and Hsiyang county in the Post-Mao era," by Tang Tsou, Marc Blecher and Mitch Meisner in Select Papers from the Center for Far Eastern Studies, No. 4, 1979-80 (1981)). The conclusion to a paper that he prepared originally for a conference I organized in 1983 on behalf of the European Science Foundation will provide a fitting end to this brief overview of his writings. (The conference volume, Foundations and Limits of State Power in China, was published by SOAS and the Chinese University Press in 1987; I quote here from the revised and enlarged text which constitutes the final chapter in the volume of Tang's selected essays cited above.) After surveying the history of the Chinese Communist Party from its foundation to the era of Deng Xiaoping, Tang wrote:

Before "socialist democracy" can be achieved, institutionalization, routinization, and acceptance in principle of the rule of law must first take place. All this is now being attempted. But how long will it take the Chinese to actualize "democracy on a high level" and "spiritual civilization on a high level"? Could it be that Chinese development in the twentieth century and beyond is like the journey of the traveler depicted in the well-known Chinese verse:

Mountains multiply, streams double back-

I doubt there's even a road;

willows cluster darkly, blossoms shineanother village ahead!

There is realism here and a hint of pessimism, but at the same time an eloquent evocation of Tang's love of China and of his Chinese roots, which provide the key to his success in writing about the country from every conceivable perspective and in every conceivable register. On the one hand, he was a University of Chicago Ph.D. and a senior figure in the social sciences there. On the other hand, he was the son of Zou Lu [Tsou $\mathrm{Lu}$ ] and proud of the fact. I still remember the glee with which he told me how, on a visit to Sun Yatsen University in Guangzhou, of which Zou Lu was chancellor from 1932 to 1940 , he had noticed that plaques in his father's calligraphy had been vandalized. When he called this to the attention of his hosts, they responded that this atrocity must have been committed by Chiang Kai-shek and his minions, thereby suggesting that, 
despite his participation in the Western Hills Faction, Zou was someone who still merited respect.

It was therefore a source of deep satisfaction and pleasure to Tang when, in 1986, he was made an Honorary Professor of Beijing University. I happened to be in China at the same time and he glowed with pride when he spoke of it. Tragically, he was stricken almost simultaneously with one of a succession of grave illnesses, which would have quenched the spirit of a lesser man. He remained cheerful and lively and continued to think and to write. His article, "Chinese politics at the top," published in the July 1995 issue of The China Journal, re-stated once again his conviction that both social science methods and a deep knowledge of China were necessary to analyse developments there:

I am advocating ... that we cross-fertilize the social sciences with Chinese history and that we move back and forth between concepts and data in the realization that social science theory will help us to understand China but should not be mechanically applied. Chinese history is so complex that it provides many hard tests for theories, models, and general propositions based on Western cases. In turn, the Chinese experience might form the basis for new general propositions enriching the theories and models that have been built on the Western experience.

Tang continued to work on what he called, in a letter to me barely a year ago, his "safari" to chase after the "white elephants" he was trying to capture in his "think piece" entitled "Explaining the Chinese Communist Revolution and regime: enriching history with the application of the logic embodied in the emergent methodological foundation of political science." I replied that I was impatient to make the acquaintance of the beast when he finally captured it. Now I fear that we will never catch sight of this particular animal, but in his published work and in his contribution as a teacher to the training of many graduate students, some of whom have become leading figures in the fiield, as well as in his optimism, resilience and intellectual rigour, Tang Tsou has left us a rich and unforgettable legacy. 